VARGAS HERNÁNDEZ, José Gpe., 1999. "Las relaciones de los fundamentos teóricos entre la "Nueva Economía Política", la "Nueva Gerencia Pública" y la "Nueva Política Social"” en Revista Instituciones y Desarrollo $\mathrm{N}^{\circ} 4$, Instituto Internacional de Gobernabilidad/PNUD, septiembre de 1999, Barcelona.

ZELLER, Norberto, 2007 (Coord.) Marco conceptual metodológico para el estudio de las políticas públicas. Buenos Aires: Dirección de Investigaciones. Instituto Nacional de la Administración Pública.

Cómo citar este artículo

Piana, Ricardo Sebastián (2017) "El Plan Estratégico de Modernización de la Administración Pública bonaerense. Un Análisis de los principios, presupuestos y los modelos. Revista Perspectivas de Políticas Públicas vol. 6 N 12: 245-274

\title{
Reforma estatal y provincias en el sexenio alfonsinista
}

State Reform and Provinces throughout Alfonsin' government

Horacio Cao

Doctor en Administración de investigador del CIAP - FCE Sulibro ḿs reciente (encol UBA. es El Estado en cuestión. Ideas y política en la Administración Pública argentina (1960 - 2015)

horaciocao30@gmail.com
Fecha de recepción:

7.9.16

Fecha de aceptación: 5.2 .17

\section{Resumen}

El trabajo analiza las políticas de reforma del Estado durante el mandato presidencial del Dr. Raúl Alfonsín (1983/89) y cómo ellas dibujaron un escenario en donde las provincias redefinirían su lugar en el ámbito de lo político y lo administrativo. El texto describe el complejo escenario que debió enfrentar el presidente, las tensiones en torno a la orientación que debía tener la reforma estatal y cómo su capítulo provincial fue procesado a partir de las instituciones federales. Ellas tuvieron un papel crucial en el reemplazo de importantes actores políticos, económicos y sociales que entraron en decadencia a partir de cambios ocurridos tanto en orden político como en el proceso de acumulación. De esta forma se relata el proceso por el cual, frente a las medidas de ajuste -que de forma fragmentaria y contradictoria adelantó el gobierno radical- las provincias lideraron la reorganización y revalorización del patrón territorial de construcción política en la Argentina.

Palabras clave: Provincias - Reforma del Estado - Federalismo - Presidencia de Raúl Alfonsín - Neoliberalismo 


\section{Abstract}

This paper focuses on the State Reform in Argentina during the presidential term of Dr. Raúl Alfonsin (19831989) and the way it prompted for an institutional setting that eventually enabled the provinces to reshape their insertion in both political and administrative stances. The article points to the complex scenario the President had to face, the political tensions stemming from the very orientation of state reform, and the articulation of frequently conflictive federal and provincial institutional levels. Together with ongoing shifts in both the overall domestic polity and the process of economic accumulation, state reform performed a crucial role in the substitution of major economic, political and social actors. Thus, we portray the process through which, in front of the adjustment policies implemented by the Radical government, the provincial states spearheaded the reorganization of Argentina's political structure.

\section{Key words}

Provinces - State Reform - Federalism - President Raúl Alfonsín - Neoliberalism.

\section{Introducción ${ }^{1}$}

En este trabajo analizamos las políticas de reforma del Estado durante el mandato presidencia del Dr. Raúl Alfonsín (1983/89) con especial atención en la situación de los Estados provinciales. Se trata de una historia poco recorrida dentro de los trabajos que se dirigen al análisis de la Administración Pública Argentina. Hay disponible en internet y bibliotecas un palimpsesto de normativa, documentación, trabajos históricos, noticias de diarios, anecdotarios, algunos (escasos) análisis organizacionales, pero poco de ello ha sedimentado en reflexiones sistemáticas sobre la reforma estatal en tiempos de Alfonsín y menos sobre su trayectoria provincial. ${ }^{2}$

El periodo histórico que analizamos se despliega en momentos en que era notorio -a nivel nacional, regional y mundial- el ascenso de las ideas neoliberales, cuyo desembarco en el Estado argentino se dio con la dictadura militar que usurpó la conducción política del país en el año 1976. Es en ese momento en que se comienza a dejar de lado al desarrollismo como ideología estatal y a reemplazárselo por las ideas de ajuste estructural.
El fracaso de la dictadura y la derrota en la guerra de Malvinas propiciaron un apresurado retorno a la legalidad constitucional en cuyo marco fue electo el Dr. Raúl Alfonsín como presidente de la Nación. Su periodo presidencial fue intenso y cambiante; en su devenir hubo la búsqueda de un camino alternativo al del ajuste estructural y ante la imposibilidad de franquear las restricciones del escenario político y económico, el despliegue de medidas de corte neoliberal inducidas por una serie de desequilibrios exorbitantes (inflación, balanza de pagos, endeudamiento, déficit fiscal).

Entre las medidas de reforma, aquellas que tuvieron una orientación descentralizadora generaron una revalorización de las provincias -tanto en lo administrativo como en lo político- y terminaron produciendo una amplificación de la importancia del patrón territorial de construcción política en la Argentina. De estos temas trata el trabajo que sigue.

\section{Ajuste y política en la Argentina}

\subsection{Los prolegómenos del gobierno radical}

Con el golpe de Estado de marzo de 1976 se inicia un nuevo ciclo en la historia argentina, cuya direccionalidad marcaría el tono de la sociedad por veinticinco años. El eje central de la dictadura giró alrededor de un programa neoliberal que, según expresó el Ministro Martínez de Hoz, venía a terminar con un periodo de "fracaso y frustración... que comienza en la posguerra del 46 ". ${ }^{3}$

Según su visión, en aquel momento se habían comenzado a generar tremendos errores en la vida pública, originados en "la intervención excesiva del Estado en la economía y... el concepto de economía cerrada” (Martínez de Hoz, 1981: 705). Para enfrentarlos la dictadura acudió a los conceptos de subsidiariedad -que implicaban privatización y descentralizaciones- y apertura económica, que justificaron políticas de liberalización (desregulación) y libre cambio en el mundo de las finanzas y del comercio exterior.

De estos conceptos se derivaron políticas concretas que afectaron severamente el mundo social pues debilitaron la estructura de empleo industrial y las instituciones que habían sido funcionales al proyecto desarrollista (sindicatos, partidos políticos, escuelas técnicas y comerciales, etc.). Igualmente, a partir de su despliegue, se construyó un nuevo bloque de poder definido por las capacidades estructurales para disciplinar a los actores populares, en particular a los asalariados. ${ }^{4}$

Los resultados no fueron los que preveían los defensores del libre cambio: la dictadura no hizo más que cosechar fracaso tras fracaso en lo económico, lo político, y lo social. En los años de la plata dulce, muchos síntomas del descalabro se mantuvieron ocultos por la enorme disponibilidad de divisas derivadas de un escenario financiero mundial caracterizado por la sobreoferta de créditos. Pero cuando las favorables condiciones internacionales cambiaron 
-la señal emblemática en este sentido fue el incremento de la Reserva Federal de los EEUU de las tasas de interés de referencia de las deudas públicas y privadas (años 1981-2)- se produjo un doble proceso de efectos demoledores: fuga de capitales e incremento vertical de los giros al exterior en concepto de pagos por los servicios de la deuda externa.

De esta manera se hizo patente, súbitamente, una situación de penuria fiscal que mostraba que la dictadura no había hecho más que profundizar la situación crítica que ya se vivía hacia mediados de los 70, cuando usurpó el poder.

Ante el escenario de desintegración y como estrategia de fuga hacia adelante, el gobierno de las FFAA -con un supuesto guiño de los EEUU- decidió la invasión de las irredentas Islas Malvinas. La derrota militar promovió una desordenada apertura democrática y el regreso a los cuarteles.

Ahora bien, si la situación ya era penosa, los gastos de guerra llevaron a la economía y al escenario fiscal hasta límites difíciles de catalogar: en 1981/82 el PBI retrocedió casi el 12\%, y el déficit fiscal anual fue del orden del 10\% del Producto Bruto Interno (INDEC, 1993: 403 y Carcioffi, 1990: cuadro I.12).

\subsection{Las dificultades de la transición radical}

En diciembre de 1983 el Dr. Raúl Alfonsín asume el primer gobierno post dictadura. A grandes rasgos, su propuesta de gobierno era la de construir un Estado de Derecho que sometiese a los poderes corporativos (FF.AA., Iglesia y sindicatos) a través de las instituciones de la democracia. Consecuentemente, consideraba que el núcleo de la problemática nacional estaba en la política y en el cambio de una matriz autoritaria por otra que promoviera las libertades individuales, el pluralismo y el rechazo de los dogmatismos. Este cambio, que se programaba como gradual, era el centro del proceso político el cual, a nivel continental, se nominó genéricamente como transición democrática.

El propio Presidente, en su discurso de asunción ante la Asamblea Legislativa el 10 de diciembre de 1983, y nada menos que en el capítulo dedicado a la economía, sostuvo que "los objetivos fundamentales de gobierno constitucional se encuentran en los ámbitos cultural, social y politi$c 0 " .{ }^{5}$ Varios autores han sostenido que esta idea de priorizar lo político sobre lo económico fue un error. Larriqueta -a la sazón funcionario económico de cotidiana vinculación con el Presidente- sostenía que esa postura fue parte de una estrategia; era tan abrumador todo lo que estaba pasando en el pás, - "las consecuencias trágicas de la violencia, la derrota en la guerra, la destrucción de su cultura" - que hubiera sido políticamente contraproducente hacer pública con toda crudeza la profundidad de la crisis económica (1988: 128).

Lo cierto es que en el momento de asumir, la situación económica era calamitosa, con un déficit fiscal fuera de quicio y en proceso de crecimiento vertiginoso: para el año
1983 se precisaba incrementar en más de un 40\% los recursos para alcanzar un presupuesto equilibrado (Carcioffi, 1990: cuadro I.12). Y no sólo eso; se debía enfrentar, además, vencimientos exorbitantes de la deuda externa, una larga crisis sobre segmentos del aparato productivo y un contexto internacional hostil con agudas restricciones al financiamiento y en un proceso de marcado deterioro de los términos de intercambio.

El escenario político nacional, aquél al que Alfonsín colocaba como principal preocupación gubernamental, era igualmente explosivo. En particular, porque las Fuerzas Armadas, si bien no habían tenido más remedio que llamar a elecciones, mantenían su poder de fuego e independencia con respecto del poder político. Como si esto fuera poco, sus cuadros consideraban en los peores términos al Presidente Alfonsín, tanto es así que todo el periodo estuvo salpicado por actividades -misas, paradas militares, renuncias estentóreas, declaraciones estridentes- que eran encabezados por efectivos retirados y en actividad.

Veamos un ejemplo: en ocasión de un acto realizado en diciembre de 1984 -en el $9^{\circ}$ aniversario del intento de copamiento del Batallón de Monte Chingolo por parte de la guerrilla ERP (Ejército Revolucionario del Pueblo) -el militar en actividad encargado del discurso de ocasión, expresó, desafiante, ante un público en el que se destacaba la presencia de ex funcionarios de la dictadura:" nos capacitamos profesionalmente velando a la par nuestras armas pard acudir nuevamente al toque del clarín cuando la patria nos lo demande" (CISEA, 1984: 67).

El gobierno, que no podía quedarse impasible ante tales muestras de insubordinación, rotó reiteradamente los mandos militares, lo que generó resultados contraproducentes, pues los nuevos jefes designados, al llegar a posiciones de comando, se mostraban tanto o más inmanejables que los desplazados.

En la esfera partidaria, la polarización electoral había puesto el foco de atención en dos fuerzas: la oficialista Unión Cívica Radical (UCR) que acompañaba al presidente con pocas fisuras y el sorpresivo perdedor de la contienda electoral, el Partido Justicialista (PJ). En los primeros tiempos de su gobierno, el alfonsinismo pudo tener la situación bajo un relativo control pues aprovechó los enormes problemas internos del peronismo para neutralizar sus ataques o realizar alianzas coyunturales de acuerdo a sus necesidades.

De las fuerzas enfrentadas en el principal partido opositor -que, a grandes rasgos podían agruparse como el ala sindical y la político territorial respectivamente- la sindical era la más poderosa y la que mostraba una oposición más frontal. En esto había razones ideológicas -en ella todavía circulaban dirigentes que se enorgullecían de haber participado de la persecución de disidentes izquierdistas en el último gobierno de Perón- pero también era respuesta a la crítica que Alfonsín había lanzado, ya desde la campaña electoral, sobre los sindicatos en relación a su escaso grado de cultura democrática. 
Por el contrario, con el ala político-territorial hubo una tendencia a establecer acuerdos y trabajos conjuntos; dentro de ella, varios gobernadores justicialistas se convirtieron en interlocutores clave de funcionarios de la Presidencia. El ámbito provincial fue, en el primer momento, un lugar en donde ambos actores -radicales y peronistas- buscaron acuerdos. Duró poco tiempo: con la enorme e incontenible crisis fiscal esas alianzas no tardaron en desvanecerse. Volveremos sobre el tema en la tercera sección del trabajo, cuando analicemos las ideas de reforma provincial en el periodo radical.

Desde la Iglesia católica, que solía expresar la opinión de los poderosos actores políticos y económicos de la saliente dictadura, se realizaban declaraciones altisonantes, como la de catalogar a la democracia recién instalada de "permisiva, anárquica, selvática, de costumbres barbáricas, anémica» o la de "denunciar" que el gobierno buscaba «descristianizam al pueblo argentino con «tanta pornografía, tanto robo y herejía» (CISEA, 1984: 20).

En este crítico escenario el gobierno pensó que podría apelar a la buena voluntad de las potencias centrales para paliar la difícil situación. Es que el proceso argentino, que hacía parte de la citada transición democrática de América Latina, había sido saludado como un proceso ejemplar. Adicionalmente, pues era un caso crítico dentro del sub continente por su carácter relativamente prematuro y, por último, por el impacto que se auguraba tendría sobre los regímenes vecinos de Brasil, Paraguay, Chile y Uruguay (como efectivamente ocurrió). De acuerdo a Atilio Borón:

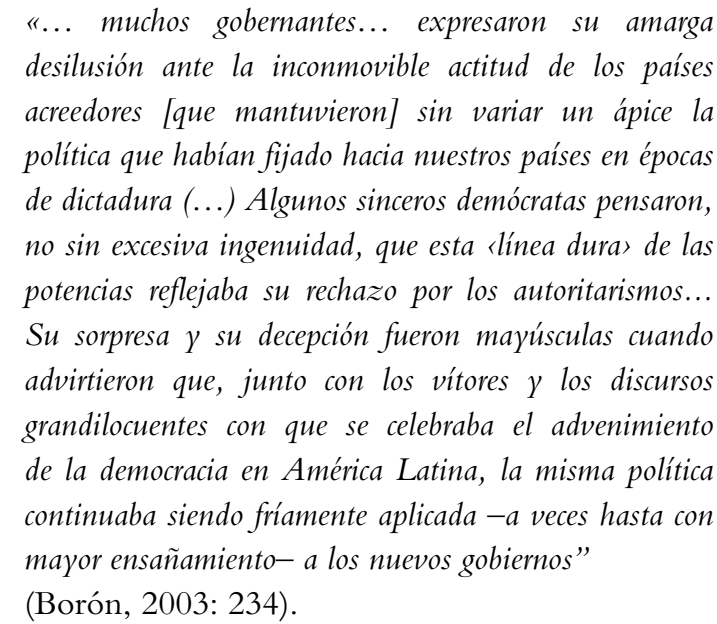
desilusión ante la inconmovible actitud de los países acreedores [que mantuvieron] sin variar un ápice la politica que habían fijado hacia nuestros países en épocas de dictadura (...) Algunos sinceros demócratas pensaron, no sin excesiva ingenuidad, que esta 〈línea dura de las potencias reflejaba su rechazo por los autoritarismos... Su sorpresa y su decepción fueron mayúsculas cuando advirtieron que, junto con los vítores y los discurso grandilocuentes con que se celebraba el advenimiento de la democracia en América Latina, la misma política continuaba siendo fríamente aplicada - a veces hasta con mayor ensañamiento- a los nuevos gobiernos" (Borón, 2003: 234).

La política internacional no sólo se dirigió hacia los países desarrollados; en el plano lationamericano el canciller argentino, Dante Caputo, fue uno de los principales promotores del llamado Club de Deudores, que agrupaba a once países de la región que firmaron el Consenso de Cartagena como primer paso para articular una respuesta conjunta al problema de la deuda. El despegue de esta estrategia fue dinamitada por el tibio apoyo que recibieron desde dos países clave: Brasil y México.

Más allá de estas dificultades, la política radical ha dejado para la historia elemento trascedentes: los acuerdos comerciales con Brasil que terminarían institucionalizándose en el MERCOSUR, los encuentros del Grupo Contadora que fueron claves para evitar la invasión norteamericana a Nicaragua, y la desmentida directa de Raúl Alfonsín al presidente de los EEUU Ronald Reagan respecto de la soberanía de los pueblos. ${ }^{6}$

Es así que el periodo presidencial estuvo jalonado por levantamientos militares, una pertinaz inflación con estancamiento económico, paros generales y el cínico apoyo de las potencias occidentales, que apenas ocultaba las presiones para que se realizara un draconiano ajuste en la economía.

En una primera etapa, el presidente Alfonsín buscó desplegar una propuesta más bien audaz de la mano del Ministro Bernardo Grispun -cuyos enfrentamientos con los representantes del FMI llegaron al nivel de leyenda- ${ }^{7}$ y el canciller Dante Caputo, que buscaba algún apoyo entre países de la región y en la socialdemocracia europea.

La soledad internacional sumada a las turbulencias internas, derivaron en un viraje hacia políticas defensivas: negociación con los organismos multilaterales, alianza con los capitanes de la industria -los referentes de las principales industrias del país- y reformas incrementales. Los resultados de esta estrategia, en términos socioeconómicos, no fueron buenos; los diagnósticos de la época hablan de estancamiento o franco deterioro y, no en vano, los '80 fueron llamados la década perdida. Según todos los análisis, estos hechos explican el descenso en la popularidad del gobierno y las derrotas electorales que sufrió en 1987 y 1989.

Pero faltaba algo más; hacia el final del mandato presidencial, el boicot combinado de las patronales rurales -que retuvieron las liquidaciones de exportaciones- y de los organismos financieros internacionales -que negaron préstamos y dieron señales de desentenderse de la suerte del Presidente- llevaron al gobierno a una situación caótica que disparó una galopante hiperinflación y, como consecuencia directa de esta, una ola de disturbios y saqueos en las principales ciudades del país. Alfonsín debió entregar el poder cinco meses antes de terminar su mandato. 


\section{El Estado en cuestión}

\subsection{La reforma del aparato estatal en tiempos de Alfonsín}

Con el despliegue de la industrialización por sustitución de importaciones -a la salida de la crisis del '30 y hasta mediados de los '70- se verificó en la República Argentina una continua ampliación de la intervención estatal, la cual en muchos casos se expresó con regulaciones y estatizaciones sobre espacios regidos anteriormente por reglas de mercado. Ya desde esas épocas, el crecimiento estatal mereció diferentes tratamientos y políticas públicas (Campione, 1996).

De la mano de las políticas neoliberales que la dictadura instaló en marzo de 1976, los planes de Reforma cambiaron el sentido histórico de la intervención estatal, pues más allá de los objetivos organizacionales y fiscales, aquellos planes se dirigieron a reformular el papel del Estado en el proceso económico-social.

En efecto, a diferencia de los procesos previos, la Reforma del Estado neoliberal no tuvo únicamente objetivos de mejora de la actividad y funcionamiento estatal, sino que, prioritariamente, buscó establecer un nuevo equilibrio Estado-Sociedad. Esta transición se estaba recorriendo cuando llegó a la presidencia el Dr. Raúl Alfonsín.

Un indicador de la importancia que se asignó al tema está dado por la creación, en el ámbito de la Presidencia de la Nación y con el rango de Ministerio, de la Secretaría de la Función Pública. Este organismo estaba dirigido a «asistir al Presidente de la Nación en todo lo referente a la función pública (...) y en todo lo relativo al mejoramiento de su desempeño a través de su examen crítico (...) como el diseño de acciones correctivas, su ejecución y seguimiento»(Decreto 134/83). ${ }^{8}$

Durante el sexenio alfonsinista, el cargo de Secretario fue ocupado por dos importantes dirigentes de la Unión Cívica Radical: en primer lugar, Jorge Roulet, de estrecha e histórica relación política y personal con el Presidente; luego de su renuncia por razones de salud, fue convocado Luis Sthulman, quien era director de la Fundación para el Cambio en Democracia (FUCADE). ${ }^{9}$ Adicionalmente, durante el período, trabajaron en la Secretaría reconocidos intelectuales dedicados al tema: Liliana de Riz, Enrique Groisman, Alberto Bonifacio, Roberto Martínez Nogueira, Isidoro Felcman, Pedro Pirez, Oscar Oszlak, Roberto Esteso, Brian Thompson, Marcelo Cavarozzi, Dora Orlansky, etc.

La idea de conducir la reforma estatal desde una Secretaría cercana al Presidente, con capacidad de producir conocimiento y conducida por dirigentes políticos de peso, era parte de la estrategia orientada a equilibrar el poder relativo del área hacendaria y dotar a todo el proceso de una mirada más compleja que aquella unidireccionalmente capturada por los objetivos de ajuste fiscal.

El trabajo compartido entre esta secretaría de la Presidencia -que planteaba los objetivos y la política en materia de administración (estrategia organizacional, política de RRHH, gestión de estructuras y funciones, etc.)- y el órgano hacendario -que influía en las prioridades con criterios fiscales- fue parte de una forma de encarar la reforma estatal que venía desde la época desarrollista (Dal Bosco, 2002: 32). No siempre generó equilibrios virtuosos ni, como en el caso que nos ocupa, se logró contrarrestar el poder del Ministerio de Hacienda, motorizado por las extremas necesidades fiscales.

Ahora bien, ¿Qué era lo que se esperaba del Estado? Como ocurre en los casos de administraciones muy condicionadas, es dificil responder la pregunta, ya que no se sabe hasta qué punto decide la interpretación de las circunstancias más que la ideología gubernamental. Para tratar de superar esta dificultad recurrimos a dos textos unánimemente reconocidos.

El primero de ellos será el documento programático más difundido durante la campaña electoral de 1983, llamado «100 medidas para que su vida cambie». Este escrito dedicaba las últimas cinco medidas a la gestión estatal:

«eficiencia en la prestación de los servicios públicos (medida $N^{\circ}$ 96). Austeridad en la función pública (...) todo privilegio será extirpado de los presupuestos (97). Se exigirá el mayor rigor en la administración de las empresas del Estado (...) La fiscalía de investigaciones administrativas será reforzada en medios y funciones (98). Las empresas privadas que han pasado de hecho a ser propiedad estatal retornarán al sector privado, si no existiera interés nacional o beneficio social significativo (99). Las tarifas de los servicios públicos prestados por las empresas del Estado deberán cubrir los gastos de operación y contribuir a la inversión (100), (Unión Cívica Radical, 1983).

Como se observa, y a diferencia de lo que ocurría con otros capítulos en donde se fijaban posiciones audaces -derechos humanos, libertades civiles, salud- en lo que refiere al Estado hubo más bien definiciones genéricas y poco profundas. Más allá de ello, es de destacar la importancia que se asignaba a los servicios/empresas públicas (tres de las cinco metas estatales referían a ellas), respecto de los cuales y a diferencia del otro gran referente partidario del escenario político, el Partido Justicialista, la UCR planteaba la posibilidad de privatizaciones. 
Otro documento, clave para desentrañar la direccionalidad última de lo estatal, es el discurso del Presidente en Parque Norte $\left(1^{\circ}\right.$ de diciembre de 1985), considerado una de las piezas oratorias en donde con mayor claridad se establecieron los objetivos y perspectivas trascendentes de gobierno. Como se recordará, el presidente Alfonsín había centrado sus esfuerzos en la lucha por desmontar el poder corporativo que, según su análisis, había contaminado de autoritarismo y rigidez todos los ámbitos de la vida nacional.

Las líneas para la reforma del Estado eran directa continuación de esta contienda, ahora enfocadas en el ámbito de la Administración Pública. Desde el gobierno se sostenía que los poderes corporativos habían capturado las estructuras ministeriales y habían generado «sucesivos regímenes de privilegio para distintos grupos». Además de la problemática propia que esto generaba, incentivaba a que el resto de los sectores de la comunidad, al ver las ventajas que se obtenían de esta situación, también se lanzasen a obtener sus propios regímenes especiales. Esto había concluido en un «Estado sobrecargado de presiones particularistas que se expresaba en un reglamentarismo jurídico cada vez más copioso y paralizante» (Alfonsín, 1985).

Salir de este círculo vicioso implicaba transformar la «sociedad bloqueada con la que culminó el ciclo precedente» en "una sociedad flexible», que permitiera pensar en la «apertura a nuevas fronteras», y que aceptara renegociar «bastiones de derechos adquiridos, nichos de privilegios que se fueron sobre agregando a nuestra legislación» (Alfonsín, 1985). La herramienta "esencial» para lograr este objetivo era la descentralización «no sólo para alcanzar un objetivo de mayo eficiencia, sino también (...) para asegurar (...) posibilidades más amplias de participación (...) dotando a los ciudadanos de cuotas crecientes de responsabilidad» (Alfonsín, 1985).

Analicemos ahora el pensamiento de Jorge Roulet. Consistente con la perspectiva de su partido, el Secretario de la Gestión Pública veía en el Estado un elemento esencial en la lucha democrática: «El nudo de todo consiste en consolidar el funcionamiento de la democracia y para ello necesitamos que el Estado cumpla eficazmente su rol de democratizador de la sociedad». Para cumplir este rol, era clave la lucha contra las corporaciones: «La Argentina corporativa quiere destruir el Estado, castrarlo y hacerlo impotente (...) buscan un Estado proveedor de excepciones para sus propios negocios». En su puja con la Argentina corporativa, deberían ser los funcionarios del gobierno los más «preocupados por su eficiencia y su eficacia... en la medida en que somos los más interesados en que funcione bien» (Roulet, 1988a: 20 y 21).

En este sentido, y así como Alfonsín en la campaña electoral de 1983 había dicho que debía colocarse «una bisagra en la historia argentina», Roulet plantea una «discontinuidad sustantiva en la forma de funcionar la administración» (Roulet, 1988a: 50. Ver también 61, 72, 77).

La discontinuidad tenía una doble faz; por un lado combatía la ineficiencia burocrática y el formalismo; al hacerlo iba introduciendo los controles democráticos y la participación para desalojar a los intereses corporativos incrustados en los circuitos de gestión; y, por otro, incorporaba el concepto de transición democrática al proceso de reforma:

«En el periodo de transición que prevemos deberán coexistir la vieja administración, en trance de transformación, con la nueva a la cual aspiramos y a la cual sólo ingresarán quienes legitimen su incorporación (...) para ello el 50\% de las vacantes del nuevo escalafón estarán reservadas" (Roulet 1988a: 66).

En el esquema ocupaba un lugar clave el Plan Patagonia, ${ }^{10}$ que incluía la idea de traslado de la capital argentina al sur, uno de los proyectos al que el gobierno radical le dedicó más energías. Este traslado podría servir como lugar de encuentro para los conceptos de discontinuidad y descentralización:

«Va a darse otro patrón de funcionamiento: llevaremos allá un conjunto diferente de personas para hacer un trabajo organizado de forma distinta, con otro equipamiento, otros métodos (...) El hecho del traslado físico de la Capital Federal va a ayudar a descentralizar el trámite de rutina y a concentrar las funciones de reflexión de diseño de políticas, de planteamiento estratégico y de supervisión» (Roulet, 1988a: 61).

Uno de los principales soportes de la estrategia de discontinuidad y transición, fue el Cuerpo de Administradores Gubernamentales (AG), creado en esa etapa y todavía vigente (Decretos 3687/84, 77/86, 1210/86 y 2098/87). Los AG eran vistos como elementos clave en el proceso de neutralizar las culturas autoritarias mediante la inserción de un nuevo tipo de empleado administrativo basado en valores de profesionalización y meritocracia, que sería una herramienta de gestión vital en el traslado de la Capital (Roulet, 1988a: 62, 73).

Otro dispositivo que alcanzó a tener algún grado de desarrollo giraba alrededor de la idea de desregulación, con la que se buscaba

"(...) depurar, $\gamma$, eventualmente, reducir, el conjunto de normas que a menudo entorpece la accion del Estado.» El «exceso de disposiciones» que, según se sostenía, habían sido «sancionadas en condiciones históricas muy distintas a las actuales y vinculadas con fines políticos que no siempre fueron compatibles con el sistema democrático», eran consideradas «en gran medida» las culpables de «las deficiencias que se advierten en la gestión del Estado» (Decreto Nº 2048/87). 
Groisman (1991: 12), funcionario de las gestiones de Roulet y Sthulman, sostuvo que este proyecto no es asimilable a la propuesta desreguladora desarrollada en el marco del ajuste estructural, pues buscaba "contrarrestar la tendencia que tiene toda burocracia a la proliferación de normas y a la complicación de trámites», a diferencia del neoliberalismo que perseguía «disminuir indiscriminadamente el número de reglas» lo que escamotea la discusión de fondo: qué contenido y qué alcance deben tener las normas.

Con menor grado de avance, desde la Secretaría de la Función Pública se desarrollaron, además, otras líneas de acción de las cuales citaremos: Desarrollo de una carrera de la administración pública bajo un esquema participativo y abierto (Groisman, 1991: 62 y Roulet 1988: 60, 64, 66), descentralización de la gestión de estructuras orgánico funcionales (Groisman, 1991: 35 y ss)., cambio de la idea de control de legalidad por la de control de gestión, en línea con hacer pública la información del Estado (Groisman, 1991: 65 y ss; Roulet 1988a: 33, 41) vinculación de programas de intercambio y asociación con otros países de América Latina Roulet 1988a: 38).

Estas líneas de acción y, en general, los elementos e instrumentos de reforma no pasaron lo discursivo pues, como ya comentamos, los desequilibrios fiscales fueron de tal envergadura que absorbieron la iniciativa del gobierno, y las acciones no financieras que pudieron lanzarse fueron intersticiales o complementarias del ajuste.

En resumen: a pesar del peso y los atributos de rango ministerial de la Secretaría de la Función Pública, el centro de gravedad de la reforma estuvo definido por las penurias financieras y por el enfrentamiento con el sindicalismo del sector púbico, que en buena parte también estuvo determinado por aquélla. En este último caso, el epicentro de la conflictividad del trabajo -que durante el sexenio fue muy elevada aún para los altos estándares de la Argentina- estuvo en los empleados estatales. Por ejemplo, en el año 1988 -que fue el año de mayor cantidad de conflictos laborales de toda la década- el $72 \%$ de los conflictos sindicales fueron del sector público (Senén y Bosoer, 2009: 251).

La visión hacendaria, como no podía ser de otra forma, respondía a las urgencias presupuestarias, y se basaba en dos conceptos: «Economía abierta y reducción del gasto público» (Secretaría de Hacienda, 1989: 256). Aún en el momento en que las medidas de estabilización mostraban sus mejores resultados, esto es, el momento en que las exigencias fiscales si bien graves, no estaban desbordando el esquema de gobernabilidad, las medidas concretas hacia el Estado que partían de Hacienda seguían vinculadas prioritariamente con la reducción del gasto público. Esto puede verse en el texto que acompañó la presentación al congreso de la ley de presupuesto para el año 1987, cuando el "Plan Austral"11 estaba en su cenit:
«El Estado se ha convertido en el objeto de un disconformismo social generalizado (...) El Estado, ese Estado abarcador y omnipotente que la sociedad argentina demandó y obtuvo durante décadas, ya no es funcional (...) El Estado ya no está en condiciones de ser ese personaje emprendedor y generoso que era antes, porque muchos de sus ingresos se han esfumando y porque han aparecido gastos nuevos"

(Secretaría de Hacienda, 1989: 64).

Básicamente, se sostenía que los ingresos habían caído por el creciente déficit del sistema de seguridad social, las dificultades para cobrar impuestos a los réditos, la reducción de la renta agropecuaria y las distorsiones que generaba financiarse por medio de la emisión monetaria. Del lado de los gastos, se remarcaba que el sistema de seguridad social no sólo no aportaba al tesoro, sino que precisaba fuentes de financiamiento adicionales, y por otro lado, estaba el pago de la deuda externa. Este asimetría entre presión social por el gasto, menores ingresos y nuevos rubros de erogaciones era lo que impedía, si no había cambio estructural, alcanzar el equilibrio fiscal.

En el mismo texto que se viene glosando, se afirmaba que la debilidad fiscal unida a la idea de que el Estado debía intervenir en todo, había concluido por dibujar un Sector Público débil, impotente, que si bien intervenía en casi todos los circuitos económicos y sociales, no tenía dirección estratégica ni objetivos claros. Por esto se proponía «(...) descongestionar al Estado para devolverle su capacidad operativa... replantear los ámbitos de su intervención (...) y dotar al Estado de una administración que sea responsable, transparente y eficaz». En consonancia con lo descrito, se hablaba de exceso de empleo público, que estaba mal remunerado y en donde se observaban grandes desigualdades y asimetrías de acuerdo a cada escalafón (Secretaría de Hacienda, 1989: 67 y 68).

Las medidas de reforma que lideraba Hacienda tenían la lógica que venimos describiendo (Secretaría de Hacienda, 1989: 80/95):

- Un potente plan de reforma tributaria, que involucró la promulgación de catorce leyes ("Una reforma impositiva de esta intensidad sólo tiene como antecedentes históricos... el frustrado intento del anterior gobierno constitucional en 1973") orientada a "corregir las graves distorsiones e inequidades que se había acumulado luego de décadas de inflación y puja distributiva".

- Medidas de austeridad sobre el gasto corriente (congelamiento de vacantes, demoras en el libramiento de partidas, retraso en el gasto de capital), que la situación de tensión con el sindicalismo peronista y las críticas que el propio oficialismo había hecho sobre este tipo de políticas, hacía poco prudente agitar. 
- Una estrategia débil y hasta contradictoria en lo referido a la reforma de la estructura organizacional del Estado, que incluía un proyecto bastante modesto de equiparación y recomposición salarial y un programa de retiro voluntario (claramente contraindicado para el diagnóstico de debilidad estatal).

- Una descentralización orientada a aliviar la sobrecarga del centro del país, lo que implicaba "un proceso de traspaso del suministro de los servicios, con preferencia a los municipios y cooperativas". ${ }^{12}$

Dentro de la reforma, hubo un capítulo dirigido a una ambiciosa propuesta de transformación de las empresas estatales de servicios y de producción, que implicaba (Secretaría de Hacienda, 1989: 80):

- La creación de un directorio de empresas publicas cuya función era "impulsar una reorganización de las empresas basada en criterios de eficiencia económica y de autonomía operativa" a partir de una "administración flexible y una gestión descentralizada".

- Cambios en la propiedad de algunas empresas estatales -que alcanzarían centralidad a partir del año 1987- y que apuntaban a la privatización parcial de SOMISA (empresa pública metalúrgica), la asociación de la estatal ENTEL con Telefónica de España, y de Aerolíneas Argentinas con la empresa de aeronavegación sueca SAS.

- El plan dedicaba varios párrafos a YPF, en los cuales defendía la necesidad desregular la actividad petrolera y proponía privatizaciones periféricas.

Resumiendo, la estrategia del gobierno de Alfonsín para con el sector público no se inscribía, en principio, en la idea del Estado mínimo. Pero, avanzado su mandato, tuvo que realizar ajustes para recuperar los equilibrios perdidos. La idea era que una vez alcanzados, se podría dotar de empuje a los contenidos más cualitativos y reconstructivos de la reforma.

Ahora bien, como el equilibrio fiscal nunca dio un respiro, ${ }^{13}$ las ideas que lo complementaban y que debían ganar fuerza en la medida que se superara la crisis -aplicación de nuevas tecnologías y rutinas de trabajo, por un lado, y a creación de un nuevo modelo de funcionario democrático y abierto a la sociedad, por otro- fueron opacándose dentro del dispositivo de reforma y nunca llegaron a levantar vuelo, ni siquiera en el plano de lo conceptual. De más está decir que con el ajuste y la austeridad como única, forzada estrategia, en el aparato estatal se hizo patente el deterioro de la infraestructura y un descenso marcado de su productividad.

\section{Las provincias en la era Alfonsín}

\subsection{El mapa de la situación provincial.}

El escenario político partidario de la presidencia del Dr. Alfonsín estuvo polarizado entre la oficialista Unión Cívica Radical (UCR) y el Partido Justicialista (PJ). A su vez, esta última fuerza estaba dividida entre un ala sindical, fuertemente opositora, y otra político-territorial, que ocasionalmente estableció acuerdos con el gobierno nacional.

Del lado radical, la propensión a acordar con el ala territorial del justicialismo surgía, entre otras cosas, de un panorama provincial mayoritariamente opositor: en las elecciones de 1983 sólo siete de las veintidós jurisdicciones vieron triunfar al oficialismo; doce provincias quedaron en manos del peronismo y tres fueron para los partidos provinciales que mostraron un oscilante apoyo al gobierno nacional. En las elecciones para renovación de gobernadores de 1987 el radicalismo quedó con sólo dos jurisdicciones bajo su mandato (Figura $\mathrm{N}^{\circ}$ 1).

\section{Figura $\mathrm{N}^{\circ} 1$. Partidos a cargo de las gobernaciones provinciales.}

Elecciones años $1983-1987^{19}$

\begin{tabular}{|l|l|l|l|l|}
\cline { 2 - 5 } \multicolumn{1}{c|}{} & Unión Cívica Radical & Partido Justicialista & Partidos Provinciales & Total \\
\hline Elecciones de 1983 & 7 & 12 & 3 & 22 \\
\hline Elecciones de 1987 & 2 & 17 & 3 & 22 \\
\hline $\begin{array}{l}\text { Cambios } \\
\mathbf{1 9 8 3 - 1 9 8 7}\end{array}$ & $\begin{array}{l}\text { Pierde Buenos Aires, } \\
\text { Mendoza, Chubut, } \\
\text { Entre Ríos y Misiones }\end{array}$ & $\begin{array}{l}\text { Gana Buenos Aires, } \\
\text { Mendoza, Chubut, } \\
\text { Entre Ríos y Misiones }\end{array}$ & Sin cambios & n.c. \\
\hline
\end{tabular}

Fuente: Elaboración propia sobre datos tomados de Base de datos CIAP (www.econ.uba.ar/www/institutos/admin/ciap/baseciap/) consultado 10/03/2014

Además del peso movilizador y de la garantía de gobernabilidad que podía otorgar el PJ por su amplio despliegue territorial, para la UCR era fundamental llegar a acuerdos pues se encontraba en minoría en el Senado de la Nación. Al respecto, debe recordarse que hasta la reforma constitucional de 1994 todos los senadores -salvos los de la Capital Federal- eran electos por las legislaturas provinciales, de allí que en la mayoría de los casos tuvieran una relación muy estrecha con los gobernadores provinciales.

En esa arena de negociación la UCR lograría resonantes éxitos en su tarea de neutralizar a las figuras más tajantemente opositoras del peronismo y lograr tanto la aprobación de múltiples leyes, como el aval de gobernadores justicialistas para diferentes medidas. Por ejemplo, es recordado el apoyo público del Gobernador de La Rioja, Carlos Menem, para el plebiscito en que se buscaba aprobar un acuerdo de límites con la República de Chile (noviembre de 1984), evento en el que las autoridades del PJ habían llamado a la abstención. ${ }^{14}$ 
En el caso del ala político/territorial del Justicialismo, la tendencia hacia el entendimiento se originaba en razones políticas -enfrentar abiertamente a un gobierno con alta imagen positiva no era una buena estrategia electoral-; institucionales -la organización federal del Estado inducía a escenarios de negociación- e ideológicas -en esta ala había menos figuras dispuestas a sostener un discurso recalcitrantemente opositor, como era más común en el ala sindical-

En la media que el tiempo transcurrió, la imagen de Alfonsín y su gobierno fue deteriorándose, la interna del Justicialismo fue decantando a favor de figuras que tenían respaldo electoral -lo que implicó sacar de la escena pública a algunos de los dirigentes más tajantemente opositores - y los acuerdos fueron haciéndose más dificiles. Inclusive, el gobierno nacional tomó nota de la situación y cambió en algún momento su interlocución en el peronismo, llegando a incorporar al gobierno, antes de las elecciones de 1987, a ministros del ala más dialoguista del sindicalismo (Ministerio de Trabajo para Carlos Alderete, secretario general de Luz y Fuerza). De más está decir que esta estrategia no ayudó a mejorar las relaciones con los gobernadores.

La situación sería más crítica aún después del ciclo electoral de 1987 que renovaba gobernadores: sólo dos provincias, Río Negro y Córdoba, quedaron en manos radicales, perdiendo la estratégica Provincia de Buenos Aires (Figura No 1). Con este triunfo electoral, el ala político-territorial del Partido Justicialista «ocupa, por primera vez, su rol de cabeza de la oposición, cumplido hasta entonces por la central obrera» (Senén y Bosoer, 2009: 248).

\subsection{Las dificultades para llegar con el ajuste a las provincias}

Los años '80 constituyeron el momento de mayor difusión de las ideas descentralizadoras en la socialdemocracia europea -países de Europa y América Latina llevaban adelante programas en ese sentido- y los múltiples puntos de contacto que el oficialismo tenía con ella impulsaba a tomarlas muy en cuenta.

Había dos perspectivas para justificar las descentralizaciones, una más ligada a la eficiencia en el gasto y otra que la articulaba virtuosamente con los procesos democratizadores. En la formulación de esta última, se establecía una vinculo ideológico entre centralización, poder militar y homogeneización social y cultural; a este nodo se enfrentaba la descentralización, asociada con pluralismo, tolerancia, revalorización de las diferencias y, por ende, de las minorías étnicas, culturales, religiosas, de orientación sexual.

En suma, la perspectiva democrática de la descentralización buscaba fomentar y contener una pluralidad de movimientos sociales y elementos de la sociedad civil a la vez que trataba de reemplazar una institucionalidad basada en normas dictadas desde un centro autoritario, por otra que introducía valores de pluralismo y tolerancia.
No era ajena a esta mirada la idea de debilitar a un Estado central que, además de ineficiente, había sido el brazo ejecutor de horribles violaciones a los derechos humanos. La avalancha descentralizadora era tan poderosa que pocos hicieron notar que todos los gobiernos dictatoriales de la región (desde Augusto Pinochet en Chile hasta Jorge Videla en nuestro país) habían sido descentralizadores.

Enrique Groisman, a la sazón funcionario de la Secretaría de la Función Pública, fue una de las voces que ya lo habían remarcado al comentar que las descentralizaciones podían ser «un recurso técnico... una delegación de poder que diversifica los rostros sin aliviar la represión» (Groisman, 1981: 44). Fue la suya una mirada aislada; en general hubo una perspectiva un tanto mágica sobre la descentralización que, recordemos, el presidente consideró en el discurso de Parque Norte como la herramienta «esencial» (Alfonsín, 1985).

Por esa época se publicitó a la provincia de Córdoba como modelo de descentralización exitosa. Visto en perspectiva, se trató más bien de un caso de reforma administrativa, basado sobre una burocracia históricamente consolidada que sostuvo procesos de desconcentración de funciones e incorporación de tecnología informática. En este marco, el proceso descentralizador hacia los municipios o de participación de la sociedad civil -como cambio del equilibrio de poder o empoderamiento ciudadano- cuando lo hubo, fue más bien endeble. En suma, las reformas emprendidas, modestas si se quiere, fueron valiosas en el contexto del generalizado desorden provincial, pero es dificil centrarlas en ideas de participación, democratización e incluso de descentralización. ${ }^{15}$

El otro caso provincial virtuoso de la época, el de la Provincia de Neuquén, se basó en que, a partir de su papel de partido bisagra en el Senado Nacional, sus dirigentes consiguieron recursos extraordinarios que una eficiente burocracia profesional -en cuyo centro estaba el mítico Consejo de Planificación y Acción para el Desarrollo (COPADE)- transformó en el último proceso exitoso desplegado bajo la lógica desarrollista. ${ }^{16}$ Visto en detalle, tampoco podía mostrarse como un ejemplo de descentralización democrática virtuosa.

Como no había casos a mostrar como ejemplares, fue haciéndose cada vez más incómodo hablar de descentralización, pues ella llevaba directamente hacia las espinosas relaciones Nación/Provincias, y a la necesaria utilización de las redes federales para su concreción. Además, este modelo tenía que superar el escollo de la mayoritaria presencia de gobernaciones justicialistas en las provincias.

En cuanto a trabajar descentralizaciones con los municipios, había poca memoria histórica en los gobiernos democráticos de las relaciones Nación/Municipios, ya que las leyes del juego implícitas los consideraban dentro del área de influencia provincial, y la coyuntura política era lo suficientemente compleja como para que el gobierno quisiera abrir otro frente de tensión con las mayoritarias huestes provinciales del Justicialismo. 
En otro contexto financiero, el radicalismo pudo haber tenido alguna chance de desplegar un modelo descentralizador pues, como vimos, mostró en el Senado capacidad para articular actividades con los actores territoriales del peronismo. Pero el escenario fiscal era tan desfavorable, que la Nación y las provincias no tardaran en enredarse en una desordenada puja por la distribución de los recursos. Dicho de otra forma: la misma situación contradictoria que el presidente Alfonsín enfrentó en el proceso nacional -con un programa y una ideología que buscaban recomponer el rol arbitral del Sector Público al mismo tiempo que las urgencias fiscales lo empujaban hacia las medidas de ajuste- se trasladó hacia el escenario de reforma provincial.

La puja Nación/Provincias, más allá de su cambiante virulencia, no contó con argumentos teóricos o políticos profundos. Al radicalismo alfonsinista le costaba defender el ajuste, y su debilidad electoral en el territorio -esto es, su menor representación provincial y municipal con respecto al peronismo- hacía imposible pasar de la visión ideal de la descentralización a los hechos concretos.

Para disputar con el oficialismo nacional, el peronismo territorial se refugiaba en su liturgia tradicional: un discurso entre desarrollista y federal que reverberaba en las clases populares pero que era poco atractivo para las clases medias interesadas en las libertades públicas y civiles que traía la primavera alfonsinista.

Sin embargo, estas construcciones discursivas -que contenían también elementos católicos $\mathrm{y}$ tradicionalistas- sirvieron ocasionalmente para sostener liderazgos regionales, sobre todo en las áreas periféricas del país, aunque sin llegar a construir una programa alternativo al del ajuste. Es más, muchas veces su único sentido fue el de dar un envoltorio ideológico -a partir de las obvias referencias a la doctrina peronista de la justicia social y el bienestar popular- a la disputa por la distribución de transferencias federales.

Por esa época se comentaba que la rutina de todo gobernador justicialista de paso por Buenos Aires, incluía una visita al opositor líder sindical Saúl Ubaldini, declaraciones a la prensa contra el FMI y la política del gobierno nacional, paso por la Secretaría de Hacienda, obtención de las transferencias que venía a buscar, cambio de las declaraciones hechas previamente por otras en donde se reconocían los esfuerzos que hacía el presidente para sacar adelante el país, su compromiso de acompañarlo y públicas instrucciones a los Senadores de la provincia en cuestión para que apoyaran la agenda legislativa del Ejecutivo Nacional.

Con el correr del tiempo, las negociaciones Nación / Provincias se fueron haciendo cada vez más dificiles, a partir del fortalecimiento del peronismo territorial y de las crecientes restricciones fiscales. Al clima de desconfianza y zancadillas mutuas coadyuvó que, vencida la ley $\mathrm{N}^{\circ} 20.221$ de coparticipación federal de impuestos hacia el final de la dictadura, casi todo el periodo se caracterizó por el manejo discrecional por parte del gobierno central de las cruciales relaciones fiscales. Hubo arreglos parciales ${ }^{17}$ pero sin remisiones automáticas y con una inflación mensual de dos dígitos, el mero adelanto o retraso de partidas implicaba premios suculentos y castigos terribles. En suma, la profundidad de la crisis hacía imposible pensar en visiones más estratégicas o funcionales o en establecer acuerdos que superaran el cortísimo plazo.

Repasemos el anecdotario de la época. En una nota de la Revista «El Despertador» (vinculada al peronismo del Interior, que, como vimos, estaba accediendo al liderazgo del en ese entonces principal partido de la oposición), Pedro Paz publicó una nota titulada "La técnica de la tierra arrasada, según Brodersohn". El trabajo es anunciado en tapa con otro título sin anestesia: «Exclusivo. Coparticipación: datos y cifras del saqueo a las provincias peronistas». En el texto se denuncia que por un lado; «se enviaron menos recursos a las provincias los cuales fueron apropiados por el gobierno nacional para pagar la deuda externa» y que, por otro, «se hace un manejo discriminatorio y politiquero de los recursos de las provincias (...) se trata, ni más ni menos, del hecho de sacar recursos que corresponden a algunas provincias para derivarlos a otras». El texto abunda en cifras que demostrarían esta situación (Paz, 1987: 32 y 33).

Por aquella época -unos días después de las elecciones de septiembre de 1987- ocurrió un hecho notable, sin muchos parangones en la historia de las relaciones intergubernamentales de la Argentina. En el marco de diferentes reuniones del grupo de gobernadores peronistas electos (en esos comicios el justicialismo había pasado de 14 a 17 las jurisdicciones en su poder) se enviaron a funcionarios designados o en funciones al Ministerio de Economía de la Nación para que hicieran lo que hoy llamaríamos un «piquete» de ministros provinciales en las oficinas del Secretario de Hacienda, Mario Brodherson.

Los ministros se quedaron allí hasta que el Secretario los atendió y le exigieron el pago de una supuesta deuda de mil ochocientos millones de Australes. Ante la negativa del funcionario nacional -que negó la existencia de cualquier tipo de deuda y desafió a los funcionarios provinciales a que mostraran la documentación respectiva- se desató una batahola de insultos y forcejeos (se denunció que los ministros provinciales intentaron retener al Secretario en su despacho), que al otro día se completó con una solicitada en donde el Secretario era declarado persona no grata.

A esta solicitada, la Secretaría de Hacienda respondió con un informe que mostraba un "comportamiento fiscal muy deficitario» de las provincias peronistas, originado en el incremento injustificado y desmedido del gasto y el empleo provincial. Esto enfureció aún más a los gobernadores electos: "Brodherson... se maneja con una insensibilidad y una soberbia inigualables... carece de capacidad intelectual... por el bien del país este señor debe renunciar" (Clarín, 27 y 28 de Octubre de 1987). Al otro día, los 
funcionarios peronistas fueron recibidos por el Ministro del Interior, Enrique Nosiglia y, poco después, el vocero del sector, Carlos Menem, a la sazón gobernador de La Rioja, se entrevistaría con Alfonsín. Del escándalo surgieron las negociaciones que terminarían en la nueva ley de coparticipación federal.

Bajo el escenario descrito, era claro que la preocupación nacional por las políticas públicas provinciales estuvo monotemáticamente ligada a la cuestión fiscal y a evitar que los esfuerzos que hacía la Nación en pos del ajuste se diluyeran en el gasto provincial. De esta forma en el marco del lanzamiento del Plan Austral, un vocero de la Nación decía:

«No hay ninguna duda de que si los esfuerzos del gobierno nacional por mejorar la eficiencia en el manejo de la hacienda pública no son acompañados por los gobiernos provinciales, será difícil cambiar estructuralmente el rol y funciones del Estado. Es así debido a la importancia adquirida por el gasto público provincial tanto en su nivel absoluto como en su incidencia sobre las transferencia del gobierno nacional»

(Secretaría de Hacienda, 1989: 97).

Y continuaba con una respuesta a lo que era el discurso de las autoridades provinciales que, como vimos, acusaban a la Nación de manejos arbitrarios:

«es de gran importancia esclarecer si las actuales tensiones sociales y políticas que enfrentan algunas provincias... se deben a la estrechez de miras o insensibilidad financier del gobierno nacional o si en cambio se originan en políticas desacertadas de empleo y gasto público provincial (...) En 1984-86 se produce un distanciamiento entre las pautas de prudencia fiscal adoptadas por la Nación y las políticas seguidas por la mayoría de las provincias, en materia de empleo y salarios》

(Secretaría de Hacienda, 1989: 97).

Se puede rastrear en los mensajes de presentación del presupuesto cómo el tema fiscal gana creciente importancia en la medida que se incrementa el déficit fiscal del conjunto Nación/Provincias. Así, los desequilibrios provinciales tienden a bajar en los primeros dos años del gobierno radical y en igual medida los mensajes presupuestarios plantean espacios de negociación. A partir de 1986 el déficit provincial es cada vez más pronunciado y asimismo el lenguaje de la relación Nación-Provincias gana en belicosidad (Figura $\mathrm{N}^{\circ}$ 2).
Figura $\mathrm{N}^{\circ} 2$. Evolución del déficit fiscal del consolidado de 24 provincias como \% de los ingresos - $1984-1988^{19}$

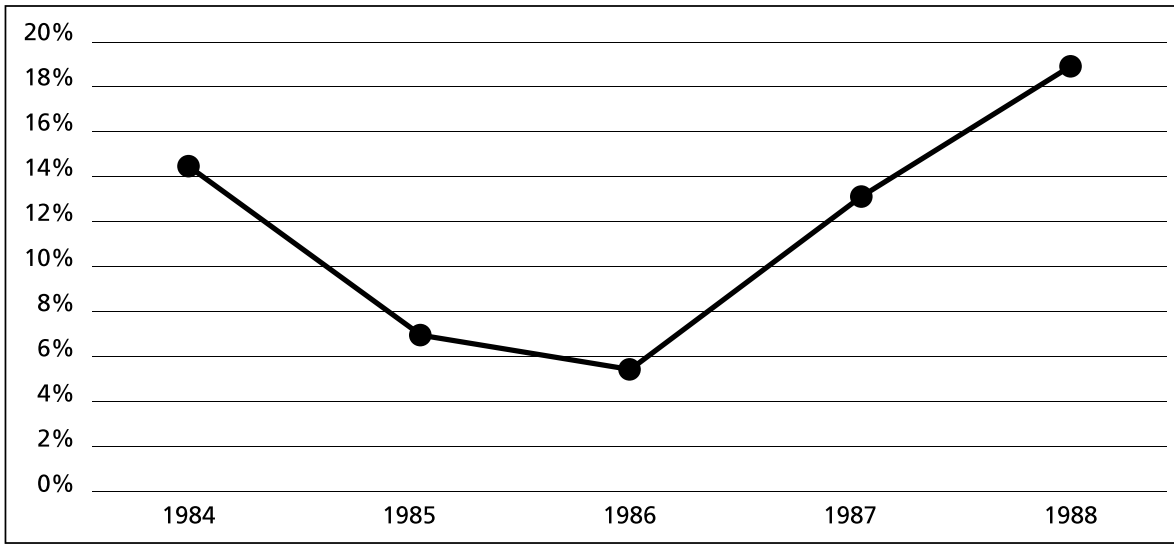

Fuente: Elaboración propia sobre datos tomados de Base de datos CIAP

(www.econ.uba.ar/www/institutos/admin/ciap/baseciap/) consultado 10/03/2014.

Hacia el final del mandato presidencial, en el mensaje relativo al presupuesto del año 1988, aproximadamente un $80 \%$ de todo el texto está dedicado al análisis de las erogaciones provinciales y las transferencias Nación/provincias. Esto es un indicador de la importancia que se le asignaba a los desequilibrios provinciales en el marco de una situación fiscal muy delicada que llevaría al hiperinflación de 1989.

En otro plano, es una pista de la apertura de negociaciones que terminarían en la ley 23.548 que estableció un nuevo régimen de coparticipación federal de impuestos. La ley fue impulsada por el gobierno cuando, luego de la derrota electoral de 1987 y el empuje de los gobernadores justicialistas, buscó el respaldo de una ley para tratar de poner límites normativos en una mesa de negociaciones que se había vuelto explosiva.

\subsection{El nuevo patrón de construcción política centrado en las provincias}

La Nación necesitaba que las Provincias redujeran el gasto y las Provincias, en la medida que vieron que el ciclo de golpes de estado había terminado, comenzaron a utilizar las potestades que le asignaba la forma federal de gobierno para evitarlo.

Esquivar el ajuste tenía un componente ideológico -en la medida en que las ideas peronistas eran históricamente estatistas- pero, más que eso, primaba el pragmatismo: el ajuste llevaba a enervar a poderosos actores provinciales y a derrotas electorales.

Sin que fuera notado ni por analistas, ni por académicos, ni por funcionarios, capilarmente estaba ocurriendo un cambio trascendente en el país: la creciente importancia de la construcción territorial de la política. En efecto, a partir de la fragmentación social 
y económica ocurrida con la reconversión capitalista y las políticas neoliberales, se producía el debilitamiento de las redes institucionales que por décadas habían sostenido la organización de las clases populares y que las había articulado con el proyecto de industrialización por sustitución de importaciones. ${ }^{18}$

Este debilitamiento llegaba, en primer lugar, a los sindicatos y a los partidos políticos, que veían menguar el enorme predicamento que habían alcanzado en las décadas pasadas. Pero no eran los únicos, también alcanzaba otras instituciones que en diferentes momentos fueron clave para la organización social: la fábrica que empleaba miles de obreros, la escuela -que crecientemente perdía influencia a favor de los medios de comunicación- la Iglesia, las empresas nacionales y sus referentes corporativos, las Fuerzas Armadas, etc. Todas estas instituciones funcionaban alrededor de un vértice de pertenencia nacional que dotaban de un denso suelo institucional y cultural de pertenencia al conjunto.

En la nueva etapa se fueron fracturando y/o debilitando las vías de articulación que describimos. El denso suelo institucional construido por las potentes instituciones enumeradas -que no era angelical, también podía ser ineficiente, agobiante y autoritarioiba desapareciendo y llevaba a que los sectores populares se debatieran en la anomia y la descomposición. En una memoria histórica estadocéntrica como la que primaba en cas todos los partidos políticos argentinos -con epicentro, claro está, en el justicialismo- no fue extraño que las provincias y, en menor medida también los municipios, se lanzara la tarea de constituir desde el sector público redes de contención para enfrentar la situación.

De esta forma es que, desde los niveles subnacionales de Estado se van construyendo espacios de vinculación postindustriales: en el barrio, a través del deporte o el arte, con fuerte presencia de acciones de asistencia social, con progresivos avances en economía solidaria, y también nucleando a movimientos sociales dirigidos a las nuevas problemáticas tales como la ecología, identidades de género o étnicas, etcétera. En la construcción de todos estos espacios, eran y son vitales la posibilidad de un diálogo cercano, de una estructura político institucional que sea capaz de expresar el cosmos regional.

La administración pública y la política provincial se pusieron en el centro de esta construcción organizándola, fomentándola, protegiéndola y, por supuesto, dándoles viabilidad financiera, política, institucional y administrativa.

Pero no era solamente el sujeto popular desperdigado que precisó de las provincias para volver a reunirse; había otros actores regionales vinculados con las administraciones provinciales que fueron claves en la nueva alianza de poder; en primer lugar, las poderosas burocracias profesionales - con la corporación judicial a la cabeza, pero también colegios de contadores, ingenieros, arquitectos-, los proveedores del sector público y todos los que de una manera u otra aspiraban a reforzar el carácter de subsistema económico social que tienen las regiones argentinas.

Todos ellos estaban ávidos de liberarse de la tutela del gobierno nacional; es decir, librarse de regulaciones y controles, y de la presencia de una administración federal en "su" territorio, que realizaba negocios -obra pública, compras y contrataciones- con agentes económicos extrarregionales.

No es casual que esta transformación del patrón político se diera de forma paralela a la decadencia de las economías regionales y de los organismos nacionales reguladores de las economías regionales (el Instituto Nacional de Vitivinicultura, la Dirección Nacional del Azúcar, Comisión Reguladora de la Yerba Mate, etcétera). Estos organismos, que habían sido claves en otro momento para el desempeño económico provincial, habían perdido importancia: hacia fines de los 80 el gasto público se había convertido en clave para la reproducción social reemplazando en esta tarea a las instituciones del sistema de Industrialización por Sustitución de Importaciones.

En otro trabajo hemos definido este proceso como expansión pasiva (Cao, 2007): la aplicación del gasto público provincial para sostener un cierto nivel de actividad productiva y estructura social, amenazada por el ajuste estatal, el cambio del patrón económico y por la mengua de las corrientes migratorias.

No se quiere imprimir en la mente del lector la imagen de mariscales políticos provinciales analizando el impacto de la reconversión capitalista en sus territorios y poniendo en marcha una planificación estratégica para contrarrestarla. Nada más alejado. Fue un ajuste continuo en el comportamiento de políticos que conocían su territorio y que habían acumulado experiencia en la relación con el gobierno central. Expertos en su oficio, fueron pulsando la realidad local y las arenas de negociación federal y, viendo que tenían herramientas para obtener recursos y que al gastarlos en sus territorios ganaban en poder político y electoral, no dudaron en elegir la estrategia descrita más arriba.

De igual forma, el autor ha descrito en diferentes artículos el carácter clientelar y prebendario con que se aplicaba el gasto y la enorme fuga de eficiencia que significó la expansión pasiva (Cao y Rubins, 1994; 1996 y 1997). No es de extrañar, entonces, que en los aparatos estatales primara la desorganización; al fin y al cabo, lo que se buscaba era la contención de los actores populares -por el lado del empleo público y la asistencia social- y garantizar la supervivencia de las burguesías regionales como tales. Al dirigirse a este objetivo, se degradaron circuitos y estructuras institucionales, pues las unidades estatales fueron inducidas a ocupar las grietas generadas por la crisis y no a cumplir las funciones específicas para las que fueron creadas. 
Pero independientemente de sus debilidades organizacionales, el esquema fue considerablemente efectivo para construir liderazgos y hegemonías provinciales llamadas a sostenerse por amplios periodos. Es así que en todas las jurisdicciones, pero en particular en las provincias de menor tamaño relativo, se organizaron desde el Estado aparatos políticos de profunda inserción territorial, que, repetimos, ocuparon un lugar vital ante el retroceso y descomposición de las redes construidas con el proyecto desarrollista y el fin de las corrientes migratorias hacia la pampa húmeda que históricamente había receptado la población que no hallaba trabajo.

Ahora bien: este esquema tiene una contradicción básica: existe y se desarrolla a partir de las transferencias desde el Estado central y necesita, para reproducirse, crecientes recursos. Esta será la batalla que quedará abierta de cara a la crisis de 1989 y que tendrá sucesivos episodios de tensión y choque en la siguiente década.

\section{Observaciones finales}

A la sombra de los procesos de reconversión capitalista a nivel mundial y de un explosivo escenario político nacional, en marzo de 1976 la dictadura militar instaló a sangre y fuego un nuevo equilibrio económico, político y social. A partir de ese momento, la iniciativa en lo político, económico y fiscal estuvo liderada por el programa neoliberal que cambió radicalmente el rol del sector público, en línea con alcanzar un nuevo equilibrio Estado-Sociedad.

En el marco de un escenario político complejo, en donde la correlación de fuerzas le impedía rechazar el programa que pedían los factores de poder, el gobierno de Alfonsín desplegó una serie de políticas para superar o al menos mitigar los graves desequilibrios económicos y fiscales sin apelar al paradigma neoliberal.

Este tensión se reflejó en las dos perspectivas de las políticas de reforma del Estado que fueron promovidas; una más doctrinaria, cuya usina era la Secretaría de la Gestión Pública, y otra más pragmática, impulsada por el Ministerio de Economía. Esta última sostenía que sin cambiar la ecuación fiscal era ilusoria cualquier política hacia la Administración Pública; en pos de este objetivo, lo único que podía hacerse era un ajuste.

En el ámbito provincial pasó algo similar, en un campo de acción que mostraba un mapa político mayoritariamente opositor. El gobierno intentó contrarrestarlo a partir de las disputas internas del Justicialismo, divido entre sindicalistas y políticos territoriales. El trato alcanzado significó que a cambio de transferencias extraordinarias -la ley de coparticipación federal había caducado- se obtuvo el favor de buena parte del ala territorial del peronismo, clave para alcanzar la gobernabilidad.
Desde las provincias justicialistas hubo algunas apariciones de un contra discurso formado por la amalgama de ideas revisionistas federales con otras de matriz desarrollistas. No era difícil descubrir que mucho de este relato era una jugada política para ejercer presión y alcanzar mejores posicionamientos en la negociación por fondos.

Desde el gobierno, las (escasas) menciones a la cuestión provincial se inscribían dentro del paradigma progresista de la participación y desarticulación del poder autoritario proveniente del Estado centralizado. Pero esta perspectiva rápidamente fue dejada de lado cuando se lanzó el Plan Austral que focalizó el esfuerzo del gobierno en la cuestión fiscal. En efecto, a partir de allí las políticas nacionales se dirigieron a recortar el gasto público en la administración central, buscando que esta conducta fuera imitada por las provincias. Frente a este objetivo, los gobernadores se mostraron desinteresados -considerando que era un problema que no los atañía- o francamente opositores, a partir de su adhesión al histórico estatismo peronista.

Subterráneamente estaba ocurriendo un cambio de proporciones; la debilidad del gobierno radical hizo que, efectivamente, las provincias incrementaran sus recursos y que con ellos construyeran una plataforma de construcción territorial que estaba destinada a impactar notablemente sobre la estructura política argentina. Esta nueva plataforma tenía dos vectores; uno, dirigido a construir un microcosmos de relaciones en el territorio sobre la base de la asistencia social, la cultura, las economías solidarias, los movimientos sociales, y otro, enfocado a sumar a la alianza a los clases dominantes, a partir de desplazar a actores de extracción extra regional. La nueva modalidad se caracterizó por su heterogeneidad; fueron notorios sus ineficiencias y sus modos de acumulación política poco virtuosos (clientelismo, prebendalismo). Más allá de ello, es indudable que transformaron a las organizaciones provinciales en el lugar de refugio y reagrupamiento de los sectores que eran agredidos por el ajuste.

Otro elemento a resaltar: en ausencia de las redes clientelares y prebendarias, no surgieron potentes economías de mercado, tal como había predicho los defensores del ideario neoliberal, sino que se extendieron la anomia y la descomposición.

Ahora bien, el modelo tenía un talón de Aquiles: para funcionar, precisaba de crecientes transferencias nacionales siendo que, justamente, la Nación estaba empeñada en bajar el nivel del gasto público. En la siguiente década seguirían las batallas en derredor de esta tensión estructural de las relaciones Nación/Provincias; habría que esperar hasta el 2003 para que otro relato cambiara el escenario paradojal y contradictorio que se construyó en el sexenio alfonsinista. 
${ }^{1}$ El presente texto es parte de una investigación más amplia, de próxima publicación, dirigida a analizar el tema en el periodo $1976-2015$

${ }^{2}$ Hay escasisima bibliografia y documentación dedicada a la reforma en provincias durante el periodo bajo estudio; la que pudo encontrar el autor fue compilada en Cao (2007). Faletti ha realizado diferentes análisis de los procesos de descentralizacion de la Argentina, que relatan, sucintamente, la situación en la etapa radical (ver, por ejemplo, Falett1, 2003: capitulo 3). Los trabajos de Escolar y Calvo son clásicos para analizar el rol de los representantes provinciales en el Congreso Nacional y en las relaciones intergubernamentales (ver, por ejemplo, la recopilacion que contiene trabajos de Escolar y de Calvo y Gibson y \{2001\}). En Cao (2008) hemos descrito ${ }^{3}$ como se vinculan los procesos de reforma y la cuestion regional con la Coparticipación Federal de Impuestos.

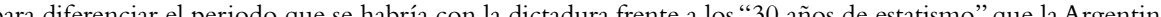
había recorrido entre 1946/1976.

${ }^{5}$ El discurso completo puede verse en http:/ / wwwyoutubecom/watch?v $\mathrm{v}=$ prDz3z Z Z8Fk, consultado el 23/02/2015. ${ }^{6}$ Fragmentos del discurso puede verse en www.youtube.com/watch?v $=$ ck27bJBhEgI. Consultado el 20/03/15. La anécdota más famosa remite a un encuentro protocolar con representantes del FMI, que derivó en una discusión cada vez más ardorosa y que concluyó cuando el ministro gritó "¿erero vos querés que me baje lo pantalones? Me los bajo .Y ante los asombrados tecnócratas se puso de pie, se desabrochó el cinturón y se bajo los pantalones. La anécdota es parte de las leyendas que circulan por los pasillos del Ministerio de Economía de la Nación y tiene dos versiones; en una se resalta la irresponsabilidad y falta de profesionalismo del ministro; 8l decreto puede verse en wwwinfoleg gob ar/infolestnternet//nexos/165000-169999/167164/nom. ,

de formación de militantes de la Junta Coordinadora Nacional, el grupo más estrechamente ligado al presidente Alfonsín.

El llamado Plan Patagonia, que preveía la deslocalización del distrito federal de la Argentina desde la ciudad de Buenos Aires hacia los núcleos urbanos erigidos y por erigirse en un futuro, en el área de las ciudades de Viedma, Carmen de Patagones y Guardia Mitre en el limite entre las provincias de Buenos Aires y Rio Negro (ley 23.512). Más allá de la aprobación de la ley, el gobierno no pudo poner en marcha el proyecto. Sus características generales pueden verse en es.wikipedia.org/wiki/Proyecto_Patagonia\#\#Historia_del_Proyecto_

"Plan lanzado por el Ministro Sorrouille en junio de 1985 y que, en una primera etapa, logró indicadores

${ }^{13}$ La estrategia del Plan Austral tuvo alguna posibilidad de éxito, en particular porque las medidas de austerida inflación, en un primer momento incrementaron los ingresos Pero coma lumada a la brusca reducción de ni por las Provincias ni por las empresas públicas, y como el contexto internacional (tasas de interés de la deuda externa, deterioro de los términos de intercambio), y nacional (derrota electoral) se endurecieron a partir de 1987, el déficit fiscal volvió a dispararse y todo se derrumbó.

"Claro esta, no solo hubo éxitos. Es recordado el fracaso en el Senado del proyecto de ley de democratización sindical (Ley "Mucc1", por el apellido del Ministro de Trabajo que la impulsó) en marzo de 1984.

${ }^{5}$ Sobre la reforma cordobesa de los 80 puede verse el trabajo de Angeloz (1995). El eje de la reforma tuvo como precondición un manejo prudente de las finanzas provinciales facilitado por un acceso privilegiado obierno de Alfonín Pocos ãos despús, la idea de presentase como modelo alternativo a juste menenista levó a las autoridades provinciales a rechazar la privatización del Banco provincial y la transferencia de la caja de jubilaciones. Los desequilibrios de ambos llevaron a la provincia a la bancarrota y a una situación explosiva que ha hecho olvidar aquella experiencia relativamente exito

${ }^{16}$ Sobre el proceso de Neuquén. Favaro, (2016). También Palermo (1988)

${ }_{17}^{17}$ Por ejemplo, el "Acuerdo Transitorio" vigente entre 1985 y 1987.

${ }^{18}$ Levitsky (2005) desarrolla este tema en profundidad.

"En 1991 se provincializo el hasta ese entonces Territorio Nacional de Tierra del Fuego y la reforma constitucional de 1994 dio estatus de Estado autónomo a la Ciudad de Buenos Aires, llegando hasta 24 los Estados miembro

de la federación que existen en la actualidad. En el periodo analizado, tanto el gobernador territorial de Tiente
Fuego como el Intendente de la Ciudad de Buenos Aires eran designados por el Presidente de la Nación.

\section{Referencias}

Alfonsin, Raúl (1985) "Discurso de Parque Norte:'Convocatoria para una Convergencia Democrática"” Discurso ante el plenario de delegados del Comité Nacional de la Unión Cívica Radical, el domingo 01/12/1985, Buenos Aires. Disponible en http:/ /www.urgente24.com/819-para-releer-alfonsin-en-parque-norte-01121985-3er-movimiento-historico, consultado el 23/09/2014.

Angeloz, Eduardo (1995) "La descentralización como reforma democrática del Estado" en Revista Aportes No 3 (10-25).

Azpiazu, Danel; Basualdo, Eduardo y Khavisse, Miguel (1989) El nuevo poder económico en la Argentina en los años 80 . Buenos Aires: Editorial Legasa.

Borón, Atilio (2003) Estado, capitalismo y democracia en América Latina. Buenos Aires: CLACSO

Calvo, Ernesto y Gibson, Edward (2001) "Federalismo y sobrerrepresentación: la dimensión territorial de la reforma económica en la Argentina" en Ernesto Calvo y Juan Abal Medina, eds. El Federalismo Electoral Argentino. Sobrerrepresentación, Reforma Política y Gobierno Dividido en la Argentina. 2a Edición, Buenos Aires: Eudeba-INAP: 199-228.

Campione, Daniel (1996) Prolegómenos del peronismo. El aparato del estado entre 1943 y 1946. Inédito. Tesis presentada en la Maestría en Ciencia Política, Instituto Universitario Patricios.

Cao, Horacio (2007) La especificidad del Estado y la Administración Pública en las provincias del área periférica de la República Argentina - $1^{\circ}$ Premio Concurso "Innovación y Mejoramiento de las Políticas Públicas”, en la Categoría Tesis de Doctorado - Buenos Aires: Instituto Nacional de la Administración Pública - Jefatura de Gabinete de Ministros Disponible en http://www. sgp.gob.ar/contenid,os/inap/publicaciones/docs/06-07_Categoria_Doctorado_2.pdf, consultado el 23/09/2014

Cao, Horacio (2008) "Ortodoxia y revisionismo en el abordaje de la Coparticipación Federal de Impuestos". Revista Aportes para el Estado y la Administración Gubernamental $\mathrm{N}^{\circ}$ 26: 121-126.

Cao, Horacio y Rubins, Roxana (1994) «La estructura institucional de las provincias rezagadas» Realidad Económica No 128:90-104. 
Cao, Horacio y Rubins, Roxana (1996) «El sistema tradicional clientelar y las Administraciones Públicas Provinciales" Cuaderno de Trabajo No 5 Universidad Nacional de Luján

Cao, Horacio y Rubins, Roxana (1997), "Técnicos y Políticos: Un clásico en la puja por el manejo de los Estados Provinciales" en Gustavo Blutman (Compilador) Investigaciones en Administración Pública Cuaderno $\mathrm{N}^{\circ} 3$ - Buenos Aires: Oficina de Publicaciones CBC - IIA - CIAP - FCE - UBA.

Carcioffi, Ricardo (1990) «La desarticulación del pacto fiscal. Una interpretación sobre la evolución del sector público argentino en las dos últimas décadas» CEPAL, oficina Buenos Aires, Documento de Trabajo No 36

CISEA (1984) Informe "El Bimestre» Centro de Investigaciones Sociales sobre el Estado y la Administración (CISEA) - Año $3^{\circ} \mathrm{N}^{\circ} 18$ - Buenos Aires.

Dal Bosco, Hugo (2002) «Reforma y organización estatal en los 600 y los 490 Documento de Trabajo, Proyecto: Estado, Sociedad y Cultura Democrática en la Reforma del Estado Argentino - Departamento de Investigación Institucional. Buenos Aires: Universidad Católica Argentina.

Escolar, Marcelo (2001) «La posibilidad de gerrymandering político. Estabilidad y concentración geográfica del voto partidario» en Ernesto Calvo y Juan Abal Medina, eds. El Federalismo Electoral Argentino. Sobrerrepresentación, Reforma Política y Gobierno Dividido en la Argentina. $2^{a}$ Edición, Buenos Aires: Eudeba-INAP (Páginas 157/198).

Falleti, Tulia (2003) «Governing Governors: Coalitions and Sequences ofDecentralization in Argentina, Colombia, and Mexico» Tesis de Doctorado - Northwestern University, Evanston, Illinois, EUA, sin publicar.

Favaro, Orietta (2016) «Partidos y democracia en Argentina. El caso de un partido provincial con éxito: el Movimiento Popular Neuquino» en Revista Perspectivas de Políticas Públicas Año 5 No. 10:29-59.

Groisman, Enrique (1981) «Función administrativa y legitimación democrática» Ensayos y Tesis $\mathrm{N}^{\circ} 2$ Buenos Aires: CISEA.

Groisman, Enrique (1991) «Políticas administrativas para el sistema democrático» Buenos Aires: Biblioteca Política Argentina No 314
INDEC, Instituto Nacional de Estadísticas y Censos (1993) Anuario INDEC 1993 Buenos Aires: INDEC.

Larriqueta, Daniel (1988) La economía radical en la tempestad Buenos Aires, Editorial Sudamericana.

Levitsky, Steven (2005) La transformación del justicialismo. Del partido sindical al partido clientelista, 1983-1999. Buenos Aires, Siglo XXI editora.

Luna, Félix (1986) El 45 Buenos Aires, Editorial Sudamericana (14ª edición).

Martínez de Hoz, José Alfredo (1981) «Discursos» en Memoria del Ministerio de Economía 19 de Marzo de 1976 - 29 de Marzo de 1981 Tomo III 3a Parte» - Buenos Aires: Ministerio de Economía.

Palermo, Vicente (1988) Neuquén: la creación de una sociedad. Buenos Aires: Centro Editor de América Latina.

Paz, Pedro (1987) "La técnica de la tierra arrasada, según Brodersohn" en Buenos Aires: El Despertador Año III No 12.

Roulet, Jorge (1988a) La incidencia del Rol del Estado en la Administración Pública Buenos Aires: Fundación Jorge Estaban Roulet - Centro de Participación Política (edición original 1981)

Roulet, Jorge (1988b) El Estado necesario Buenos Aires: Fundación Jorge Estaban Roulet - Centro de Participación Política.

Secretaría de Hacienda (1989) «Política para el cambio estructural en el Sector Público Poder Ejecutivo Nacional, Ministerio de Economía, Secretaría de Hacienda - Buenos Aires.

Senén González, Santiago y Fabián Bosoer (2009) Breve historia del sindicalismo argentino. Buenos Aires,Editorial El Ateneo.

Unión Cívica Radical (1983) «100 medidas para que su vida cambie. Síntesis de la plataforma radical». Buenos Aires, Unión Cívica Radical.

\section{Cómo citar este artículo:}

Cao, Horacio (2017) "Reforma estatal y provincias en el sexenio alfonsinista". Revista Perspectivas de Políticas Públicas vol. 6 No 12: 275-303. 